with Dr. Dianne Smith

\title{
Resurfacing Memories: Mnemonic and tactile representations of family history in the making of new heirlooms
}

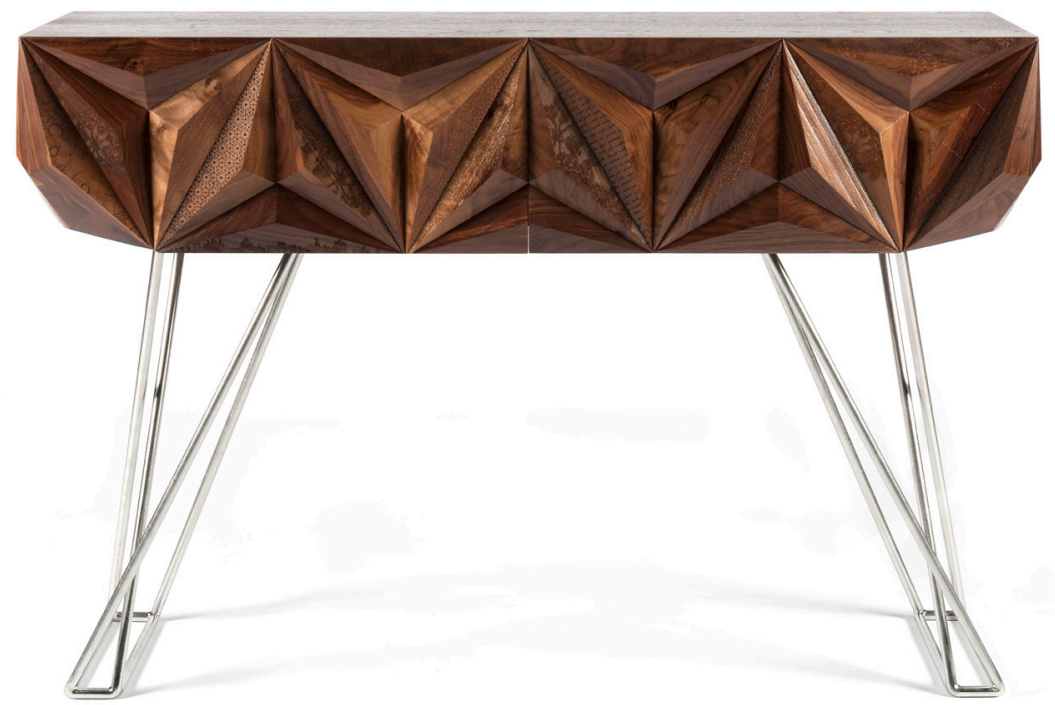

Fig. 1 Author (2013). The Unforgotten hall cabinet [Front view, Photograph, Eva Fernandez courtesy of FORM]
The Unforgotten is a functional furniture piece that challenges current conventional industry design practices which seek to achieve object longevity and heirloom quality through realising the status of a 'design classic'. By taking a design anthropology approach to understand the person-object custodial relations, the creative work aims to embed a long-term attachment for the possessor by encouraging emotional attachment and custodian behaviour. As such, research was conducted in the areas of consumer psychology and behaviour, object attachment, inalienable objects and custodianship.

Anti-obsolescence approaches such as quality craftsmanship and materials no doubt contribute to longevity in terms of durability (Pye \& Nevelson, 1973). However there exists a significant omission in design discourse regarding the potential for object lifespan extension through recommodification (Gregson \& Crewe, 2003) and the inalienability of manufactured objects. Even when durable and still functioning, objects that are no longer desired by the possessor are typically assigned to the waste stream, often being replaced with equally short-term products (Botton 2004; Mugge, Schiffersteinn, Schoormans, 2010; Naish, 2008). However when objects have a "singularised" and "storied life" (Epp \& Price, 2010), 
and are recommodified or rendered inalienable, their lifespan can be significantly extended (Belk 2006; Karanika \& Hogg 2012; Mugge et. al., 2010).

Design discourse often characterises 'new heirloom' furniture-that is, furniture that will be intergenerational and evade premature disposal-as 'classic' (Hebrok, 2014: 213), modernist, and typically non-decorative (Schiermer, 2016; Simmel, 1997). However this belief is challenged when examined through an anthropological perspective of person-object relationships. Anthropological findings indicate that a significant characteristic of inalienable heirloom objects is that they are emotionally laden and mnemonic of significant life experience, rather than being generated from the object's physical characteristics (Csikszentmihalyi \& Rochberg, Halton 1981; Mugge, et. al., 2006). Objects that are conducive to intergenerational ownership, namely those re-commodified, are not dependent on modernist, visual forms per se (Curasi, Price, Arnold, 2004; Epp et.al., 2010; Gregson \& Crewe, 2003). Therefore addressing durability and longevity materially, without addressing the individual or social attachment, or conversely how disconnection to objects occurs, potentially results in a mismatch between the material and emotional or social longevity, and thereby premature disposal of functioning furniture.

Consumer behaviour studies in custodianship and collector behaviour further reveal the importance of memory and experience with objects post-acquisition. In fact, custodian and collector behaviour demonstrate the potential for individuals to invest significant time, energy and care into ensuring object longevity, often with the aim of bequeathing or passing the object on to others (Belk, 2006). The findings from these studies of person-object relationships tell a great deal about the potential role designers can play in facilitating object longevity by encouraging custodianship through embedding memory or experiential opportunities.

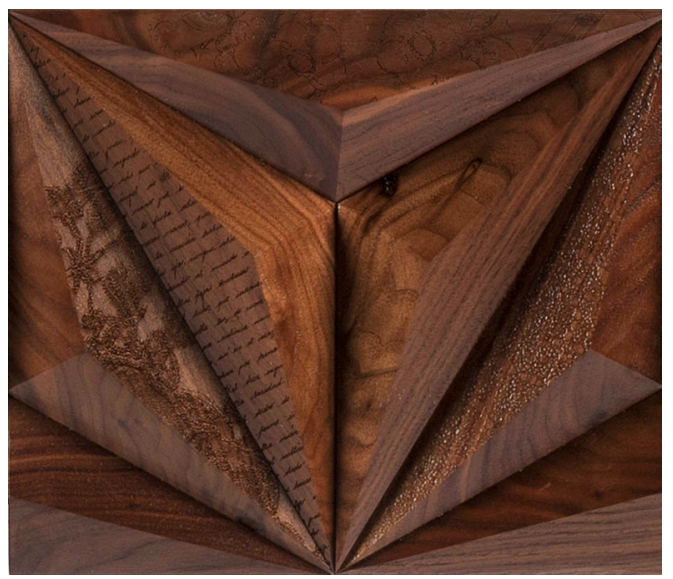

Fig. 2 Author (2013). The Unforgotten [detail, Photograph, Eva Fernandez courtesy of FORM]

Fig. 3 Author (2013). The Unforgotten [detail, Photograph, Eva Fernandez courtesy of FORM]



The phenomenon of object attachment has typically been understood in anthropomorphist terms - that is according to correlates with human features or modes of animation (Chandler \& Schwartz, 2010) or, in the case of electronic artefacts, through user experience (UX). However, The Unforgotten project developed here exemplifies the opportunities for emotional inalienability present in tactile experience and the mnemonic qualities of objects. 


\section{A Hallway Cabinet}

To firstly address the measurable, durable qualities, the object is made of stainless-steel rod and solid American Walnut timber to ensure material longevity and potential surface renewal as it ages. The timber is finished in natural, non-toxic furniture oil and wax. As the entry of the home is a powerful signifier of personal space and identity, The Unforgotten hallway cabinet was thus designed as an entry marker reflecting the essential concerns of the resident, one that intertwines emotional gravitas with product durability.

The geometric and facetted timber front and sides of the cabinetwork facilitate the expression of past memory as a collage of distinct life episodes stitched together in a traditional quilt style narrative similar to previous creative works of the author (Forlano, 2015). The cabinet's form creates a series of variegated surfaces into which the narrative of the client can be read as distinct, yet connected stories, in order to reify social relations and memory.

Evocative of the incompleteness and disjointedness of memory, some facets are left unmarked whilst others are engraved. Custom laser engraving to facets draw the viewer into a detailed attendance, inviting intimacy through a close encounter with textural surface and potential touch. This invitation to be drawn into the work is further reinforced through the intricacy of the surface detailing representing meaningful family possessions, stories, events and places.

Through an informal interview it was revealed that the client possessed some disparate and highly personal objects kept hidden for over sixty years in a small box. This served as the driving force to reflect personal history and intergenerational narrative in the hallway cabinet-a long-recognised furniture type for holding and retaining. These objects-the only physical possessions remaining of the client's mother after her passing during childbirth-had been stored away

Fig. 4 Author (2013). Photograph of original hand-embroidered silk lace handkerchief

Fig. 5 Author (2013). Scan from notebook of handwritten transcribed poetry so as not to be damaged through handling, light, or other intrusive environmental factors generated across time. Amongst the possessions were her mother's own handmade silk lace embroidery, hand-written poetry, newspaper cuttings, and hand-drawn diagrams of embroidery never completed.
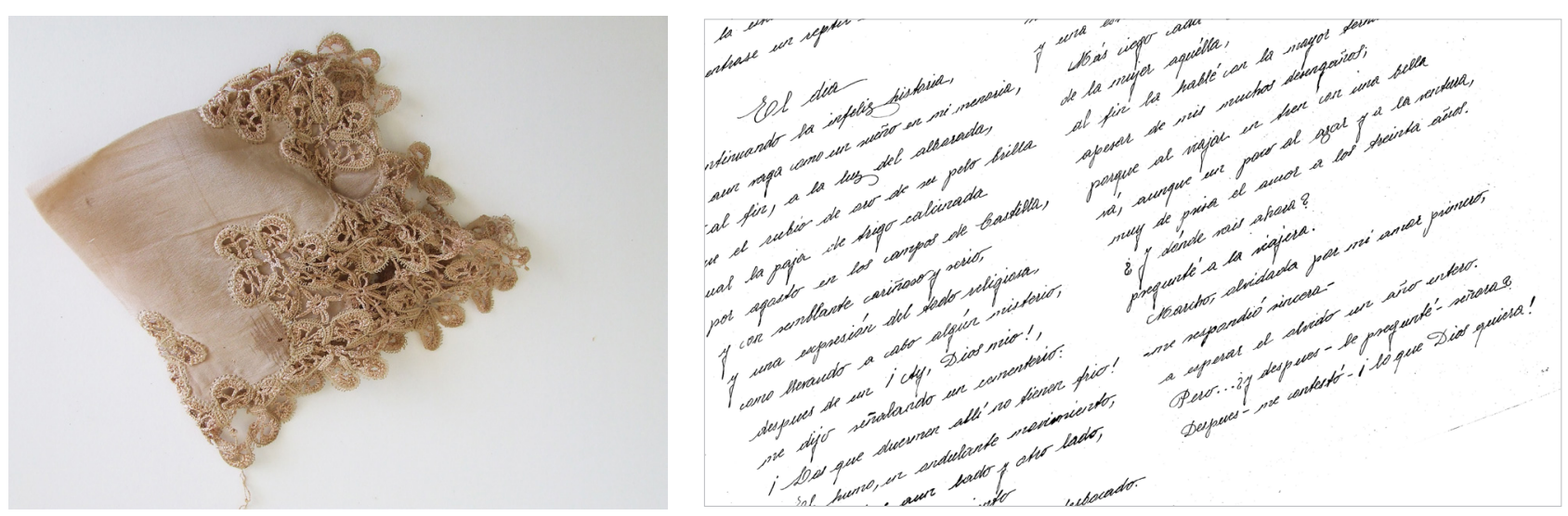

The texture of the silk, now partly decomposed, is captured in the cabinet's surface treatment. It reflects a moment in time, and the time in between spanning its first completion in 1950 and sometime in the future when it will have completely decomposed. Surfaced in the cabinet is both the 'thing' (the silk) as a 
tangible object, and the 'time' constituting an intergenerational/heirloom object. As a further example, the hand-written words and diagrams on pieces of decomposing paper are now inscribed in a more robust material, whilst also providing a new character not evident in the original possession-that is, the texture of the text as engraved material.

Through digital processes including 3D laser engraving, the characteristics of the 'things' become both visual and textural, eliciting an invitation to touch and become more familiar with the previously 'untouchable' precious object. As Stewart states:

The transitivity and motility of touch are key to legends and myths of animation...There is a carrying-over from experience to experience of the experience a kind of doubling which finds its illustration in the image of a living thing, bringing a dead thing to life through the transitivity of touch. Sleeping Beauty.....and other stories emphasize the vivifying power of gestures of love and attention (through making and reciprocal touch). (1999: 33)

Combining the various representations as a narrative of personal memory with the intricate and tactile surface qualities, the furniture object ensures an intimate engagement with the work of this other ancestor. Furthermore, what was once hidden away has now been recovered, and presents significant life memories, bringing the intimate family stories and the past back into the living present, and therefore into the everyday.

The work does not gain its meaning through physically presenting or being a container for personal things, rather inalienable and precious things are presented and embedded within the materiality of the artefact itself. As a result, this contemporary object takes on both the inalienable character of the original decomposing or fragile artefact, and it provides the opportunity for new, richer meaning within its fresh context, meaning that extends the life of the original decomposing artefacts.

Through simulation and representation of the inalienable, what is precious and potentially erasable is made viewable and touchable every day. In this way, the work demonstrates the potential for new, everyday home possessions to become inalienable and to rethink what the design of the 'heirloom' can mean. 
REFERENCES

Belk, R. (2006). Collectors and collecting. In C. W. K. Tilley, S. Küchler, M. Rowlands, \& P. Spyer (Eds.), Handbook of material culture (pp. 534-545). London, UK: Sage Publications.

Botton, de A. (2004). Status anxiety. London, UK: Hamish Hamilton/ Penguin Books.

Chandler, J. \&. Schwarz, N. (2010). Use does not wear ragged the fabric of friendship: Thinking of objects as alive makes people less willing to replace them. Journal of Consumer Psychology, 20, 138-145.

Csikszentmihalyi, M. \& RochbergHalton, E. (1981). The meaning of things: Domestic symbols and self. Cambridge, UK: Cambridge University Press.

Curasi, C. F., Price, L., \& Arnould, E. J. (2004). How individuals' cherished possessions become families' inalienable wealth. Journal of Consumer Research, 31(3), 609-622. Retrieved from http://www.jstor.org/ stable/10.1086/425096

Epp, A. \& Price, L. (2010). The storied life of singularized objects: Forces of agency and network transformation. Journal of Consumer Research, 36(5), 820-837.

Forlano, P. (2015). Making custodians: Furniture as intergenerational objects. In procedings of the Unmaking Waste 2015; Transforming Production and Consumption in Time and Place conference held in Adelaide, Australia, 22-24 May, 2015. Adelaide: Zero Waste SA Research Centre for Sustainable Design and Behaviour, School of Art, Architecture and Design, University of South Australia. Retrieved from http:// unmakingwaste2015.org

Gregson, N. \& Crewe, L. (2003). Second-hand cultures. Oxford UK: Berg.

Hebrok, M. (2014). Design for longevity: Taking both the material and social aspects of product-life into account. Journal of Design Research, 12(3), 204-220.

Karanika, K. \& Hogg, M. K. (2012).

Trajectories across the lifespan of possession-self relationships. Journal of Business Research, 66(7), 910-916.

Mugge, R., Schifferstein, H. N. J., \& Schoormans, J. P. L. (2006). A longitudinal study on product attachment and its determinants. European advances in consumer research, 7, 641-647.

Mugge, R., Schifferstein, H. N. J., \& Schoormans, J. P. L. (2010). Product attachment and satisfaction: Understanding consumers' post-purchase behavior. Journal of Consumer Marketing, 27(3), 271-282.

Naish, J. (2008). Enough; Breaking free from the world of more. London UK: Hodder \& Stoughton.

Pye, D. \& Nevelson, M. (1973). The nature and art of workmanship. Leonardo, 6(1), 94-95.

Schiermer, B. (2016). On the Ageing of Objects in Modern Culture: Ornament and Crime. Theory, Culture \& Society, 33 (4), 127-150.

Simmel, G. (1997). The philosophy of fashion. In D. Frisby and Mike Featherstone (Eds.), Simmel on culture: Selected writings (pp. 187-206). London, UK: Sage Publications.

Stewart, S. (1999). Prologue: From the Museum of Touch. In M. Kwint, C. Breward, \& J. Aynsely (Eds.) Material memories; Design and evocation, Oxford, UK. Oxford International Publisher. 